\title{
"La Carroza del Santo Sacramento" de Próspero Merimée*
}

por

Harri Meier

De los trozos del Théatre de Clara Gazul, al que Goethe, en sus Conversaciones con Eckermann, le dedicó tantas coronas de laureles (1), La Carroza del Santo Sacramento ha sido, sin duda, la más vivaz, y tambiến en la escena, la más vital. Poco representada de inmediato, la decencia de su colorido local y la elegancia y ligera frivolidad de los diálogos, estimularon hasta hace poco tiempo a Copeau a llevarla a las tablas en el Vieux Colombier (1920), habiendo hecho la Comedia Francesa un nuevo intento en 1930, no completamente feliz, para aclimatar su verbo (2). El pequeño Opus, que Merimée representó como Opereta, es por sí mismo un capítulo histórico de teatro: los más originales elementos del "Sayne$t e$ " de Merimée, derivan del libreto de Meilhac y Hálevy, que, en una carta a Gast, ponderó Nietzsche en los más cálidos términos, clasificándola como "la obra bufa de la más elevada jerarquía". El Libreto tuvo también hace pocos años una interesante traducción alemana, así como una modificación de Karl Kraus. De ninguna manera se ha agotado con ello la influencia de nuestra Carroza: constituye una nueva e importante fuente para la percepción de las condiciones sudamericanas en el siglo XVIII (3), continúa viviendo en varias obras épicas hasta El Puente de San Luis Rey de Thornton

(*) Debemos expresar nuestra gratitud al Dr. Harri Meier, Director del Seminario de Filología Rnminira de la Iniversirlad de. Bonn nnr habernoc neorgarin s" autorización para traducir este trabajo en forma exclusiva para Letras. Extendemos, asimismo, nuestro agradecimiento al Dr. Aurelio Miro Qucsada Sosa, ex-Kecior de esta casa de estudins, por habernos puesto sobre la pista de este interesanic trabajo, lo que por otro lado nos deparó la satisfacción de conocer personaimeiútic en Bonn a su autor el profesor H. Meier, en el otoño de 1964. (E. N.).

(1) Conversación del 21 de enero de 1827,3 de mayo de 1827,7 de marzo de 1830,15 de febrero de 1832, y otras.

(2) Compárese P. Meriméc, Théatre de Clara Gazul. ed. P. Martino (Los textos franceses). 1929.

(3) Z. B. N. Daireaux, El Amor en Amérlca del Sur, Paris, 1930, Cap. IX (La Realeza del Capricho). 
Wilder (4), y puede haber contribuido a influir, finalmente, las muchas leyendas que se tejieron en Sudamérica en torno de la "Perricholi". (5).

La Carroza del Santo Sacramento apareció primeramente en jumo de 1829 en la Revue de París, y, como Luccasion, fue posteriormente incorporada al Theatre de Clara Gazul. La accion se desarrolla en Lima, L'Occasión, en La Habana. ¿Cómo se puso Merimée en esos años en contacto con estos temas y amplió su horizonte sobre la América hispánica? Pierre Trahard, una especie de Torre de Saint-Jacques, de la que han salido en el futuro todas las percgrinaciones a través de la obra de Merineé, observa: "A decir verdad, sobre la elaboración de estas dos piezas, no tenemos datos más detallados que sobre la elaboración de las cinco primeras" (6); presume que un íntimo amigo de la familia Merimée, el doctor Roulin, gue justameñte ácábátú de regresar de América del Sur, le contó a él la historia de la Perricholi, la cual le vino como anillo al dedo, empeñado como estaba en su búsqueda de temas exóticos (7). ¿Debió Merimée en este caso apartarse de su costumbre de utilizar los frutos de sus lecturas como temas de sus obras - una costumbre que han confirmado las nuevas investigaciones en las fuentes-, y caminar a base de una información oral? Esto no parece verosímil, como lo demuestran las siguientes explicaciones.

La América hispana ha jugado un rol importante en la política, en la economia, en la literatura francesas, desde principios del siglo XVI: Ga expedición Franz ${ }^{5}$ I, la exportación francesa a puertos españoles ly portugueses, el eco de Las Casas y de otros en Los Ensayos de Montaigne, son los primeros testimonios de estas relaciones que sobrevivieron a todo el Antiguo Régimen. Pero jamás había cobrado tan vivo carácter este interés de Francia en las posesiones que su vecino español tenía en ultramar, como en los años de la Restauración: las colonias españolas aprovecharon el tambaleo del

(4) Compárese W. Fischer, El Puente de San Luls Rey de Thornton Wllder y La Carroza del Santo Sacramento de Próspero Merlmée. (Anglia 60, 1936, páginas 234-240).

(5) Entre otros Tradiclones Peruanas de Ricardo Palma II, Madrid o. J., Pág. $316-323$ (Genialluades de la Perricholi); Luis Albcrto Sánchez.. "La Pcrricholl", Santingo de Chile 1930. Compárese también I. A. de Lavalle. "La Perricholi". (eń: Estudios Irlstéficos, Lima 1935) L. A. Sánchez. A. de Lavalle, "La Perricholi (en: Estudios 20): M. de Mendiburu, Diccionarlo histórlco-blográflco del Perú, I, Pág. 223 ff.) (2a.
cdición, asimismo).

(6) P. Merimée, Primeros Ensayos, Théatre de Clara Gazul, ed. P. Trahard (Obras completas) Paris, 1927, pág. XLII, y aclemás pág. 492-495.

(7) Compárese P. Trahard, La Juventud de P. Merlméc II. Paris 1927, pág. 75; P. Saisset, Rev. Bleu. 6 de febrero de 1932; A. J. Roche. R. Litt ,Comp. 14, 1934, PÁg. 549 ff.; P. Trahard, RHLF 41, 1934, pág. 250 ff. y otras. 
trono español, introducido por Napoleón, para la preparación de su Emancipación política, y amenazaban entonces en una zona de inlluencia única de las dos potencias anglosajonas que dominaban el mar en América y Europa. Las guerras hispanoamericanas de Independencia, fueron simultáneamente una continuación de las contradicciones entre legitimistas conservadores y liberales, que se extinguían lentamente en Europa. Estos acontecimientos incitaban en Francia el surgimiento de una profusa literatura sudamericana, política, económica, histórica y sociológica, que correspondiendo completamente a la situación política (8), alcanzó en los años 1817/19 y 1824/27, cuantitativamente, su más alta expresión (9). Merimée siguió estas publicaciones con un vivo interés político y sociológico.

Entre las obras mencionadas, ocupó un sitio especial la Descripción de Viaje de un inglés, el capitán Basil Hall, hecha en dos tomos, "Viaje a Chile, Perú y México, durante los años 1820,1821 y 1822", que, con este título apareció en 1825 en traducción francesa, después de haber sido ya precedida por tres ediciones del original y una traducción alemana (Stuttgart, Cotta, 1824-25): la gran difusión de esta obra (10), se debió a un fino don fisionómico y psicológico de observación, a marcados intereses sociológicos y a un arte precioso de representación. Muchas son las anécdotas que hubieran podido suministrar tema a Merimée, sensible a las anécdotas impresionantes y características, para sus dramas cortos o sus novelas, tanto más cuanto que ellas venian al encuentro de sus simpatías políticas al promediar sus veinte años. Pensamos un poco en la historia del Padre confesor que le negó la absolución a su confesada, porque ella había sido educada a la française y a la que, sin más tardar, se desterró del país, por infracciones contra la nueva Constitución libre (I, $167 \mathrm{f}$ ) y por otras cosas más. A esta historia anecdótica de Hall pertenece también la de la Perricholi. (I, pág. 223-226) (11):

(8) Connórese: Gulllermo de Humboldt y la posiclón de Prusla en la guerm de Independencla hlspano-americana. Iberoamerikan]sche Rundschau III. 1937/38, pág. 347 it.

(9) En la Biblioteca Nacional de Parfs encontramos nueve escritos referentes directamente a Sudamérica para 1817. (Signaturas: Pm. 2, Pq. 53,01 530-538). $1813: 7$. 1819:5, 1824:9; 1825:8, 1826:11, 1827:7.

(10) Ediciones francesas: Parls 1825 y Parls 1834.

(11) Ins fuentes hispann-americanas dan en general un origen italiano a la forma del nombre Perricholi: Periccioli $y$ otros. El orisinal inglés (Extracts from a Journal written nn the Coasts of Chlle. Peni and Méxlcon.... I. Pár. 236-239) consiena La Perricholé, la traducclón francesa de la obra de Hali, Péricholé, por razones resrnnocidas. Merimés: Pericholc (también Direaux): otros autorcs franceses Perichole - Perischol. Hálévy y Karl Kraus exigen sin razón aparente la pro. nunciación Perikol. 
"En el momento en que regresábamos, se escuchó, de súbito, el sonido de una campana. Una brillante carroza de un gusto anticuado salió del palacio que ocupa uno de los lados de la plaza, dirigiéndose hacia la catedral, donde subió en ella un sacerdote, llevando el Santo Sacramento. La carroza se encaminó lentamente en dirección de la casa de un moribundo. Es así como, desde hace varios siglos, se lleva la Extremaunción en Lima: he aquí lo que me ha contado a este respecto una persona a quien le placía presentarme el tiempo pasado desde un punto de vista divertido:

"Hace algunos años, un virrey se enamoró apasionadamente de una célebre actriz llamada la Perricholi; y como los vicemonarcas, tanto como los mismos monarcas, jamás suspiran mucho tiempo, la señora Perricholi fue muy pronto instalada en el palacio del gobernador. Ella gastó sumas considerables; y tan bien, que por su lujo y sus impertinencias, su augusto amante llegó a ser más despreciado todavía de lo que lo había sido antes. Se adelantaba a los deseos de la Perricholi; cada objeto que solicitaba, le era acordado de inmediato. Sin embargo, una vez, uno de sus caprichos le suscitó alguna resistencia. No se trataba sino de una bagatela, a la que, empero, ella le concedía un gran valor: quería que se la pasease por las calles de Lima en una carroza que le pertenecía. Un capricho de esta clase, nada hubiera tenido de particular en Londres o París. No hay amante de una clase un poco elevada que no se considerase feliz de salir con la suya a precio tan barato. Este placer, que nos parece tan sencillo, tiene una gran importancia en la capital del Perú. A cualquiera le es permitido exhibirse en calesa, dónde y como le convenga; pero es un acto temerario, una culpable ambición, aspirar a la carroza. Lujo tal no es permitido sino a las personas de alta categoría. El virrey puso en juego todo para hacer entrar en razón a la Perricholi; su elocuencia y sus ruegos se fueron al aire; nada pudo sacar esta locura de la caheza de su amante. Hubo que resignarse, pues, a desafiar a İa opinión. A pesar del temor al ridículo y las posibilidades de una revolución, se pidió la carroza. La dificultad principal era evitar las pifias con que se la había amenazado al atravesar las calles. No se le ocultaba al virrey, que si la Perrichoili saíía sola, podía ocurrirle una desgracia. Por otra parte, él no podía ponerse al lado de ella: hubiese sido aquéllo una abominación cuyo solo pensamiento lo hacía estremecerse. Por felicidad, la caprichosa dama no exigía tanto; no tenía sino un deseo: ir sola y en su propia carroza. Se determinó al fin. que el virrey se haría conducir en su carroza, que la Perri- 
choli lo seguiría, y que la escolta y los demás carruajes del séquito vendrían después. El cortejo se encaminó en ese orden. Se ha pretendido que el virrey mandó poner una ventanilla detrás de su carruaje, a través de la cual pudiera contemplar a su antojo y a cada momento a su tierna amiga. El populacho se divirtió bastante con esta comedia, lanzando gritos de alegría durante el desfile. La Perricholi se detuvo ante la catedral; declaró que había sido satisfecha su ambición y que no quería más carroza; en su reconocimiento para con el cielo, consagró el noble don del virrey al servicio de la iglesia, expresando su deseo de que, en el futuro, la carroza fuese destinada a llevar al sacerdote y la extrema-unción".

Nada es más verosímil que Merimée hubiese sacado de la conocida obra de viaje de Hall, aparecida pocos años antes, el tema para su Carroza. En la dramática elaboración de su corto relato, su intención principal era condensar en un diálogo tallado y reflejado juguetonamente, las relaciones del incapaz virrey, doblemente despreciable y ridículo por su amor esclavo, con la impertinente y vanidosa amante, $y$ en un retrato breve y psicológico; y prestar al todo, mediante una nota de color local, un interés romántico, histórico-cultural, junto a lo psicológico-idiomático. Cómo contribuyó Merimée, por su conocimiento de la comedia francesa de los siglos XVII y XVIII y de la literatura española, con muchos materiales para este trabajo, queda explicado por Trahard en sus pruebas originales, para muchos lugares y motivos (12). La manera como el señor y el sirviente tratan de aprovechar para sus propios fines, en la escenaede introducción, las debilidades mutuas (compárese Harpagón y Maitre Jacques en el Avaro), en la que la Perricholi saborea su poder sobre el enamorado virrey, y mantiene al mismo tiempo despiertos sus celos, la conciencia de su debilidad, su paternal complejo de protector y su necesidad de amar, todo ello es tradición francesa y ha sido imitado ora del Misántropo, ora del Gil Blas, de Marivaux o de Beaumarchais. Si las figuras de actrices de Lope, Calderón y Cervantes, que Trahard señala, apenas han ejercido sobre ella una influencia penetrante, eso es por su forma, por el rol especial que juegan sus pequeños pies en los cuadros españoles de Merimée, por su idioma (acaricia con "Andresillo", la Carroza le es a ella más apreciada que una mina de plata o un departamento Indio, y así sucesivamente); por su castellano orgullo de raza y muchos otros ras-

(12) Compárese La Juventud II. pág. 110,395 f; tambićn Trahard en la citada edición del Théatre.... pág. 496-501. 
gos (ella cita a Calderón, adora, como Carmen, una corrida de toros, etc.), muy finos a menudo, y frecuentemente hispanizados o sudamericanizados con medios baratos.

La confronta el poeta con un viejo paralítico, celoso, desesperanzado en el amor, y ciego amante que se le aparece, señor sólo por su sed de títulos y representaciones y por sus aires autocráticos y repentinamente coléricos, a las manífestaciones de cuyo corazón y a sus arrebatos de rabia les ponen un límite estrecho los agudos dolores de su gota en los miembros. También esta figura de opereta de poca prestancia, trac aquí y allá diferenciados rasgos del arsenal de la literatura cómica francesa del Antiguo Régimen. Sólo por el hecho de que ella nos lo presenta aquí como virrey, refleja ella modernas tendencias: "Los reyes han sido hechos hombres; a veces son amados, pero no ya adorados". (13) ¿Ha elegido Merimée el escenario de Sudamérica, de actualidad en 1829, y la acción de la Perricholi, para suministrar su contingente en el esclarecimiento de los acontecimientos coetáneos, de la insurrección de los países ultramarinos, hijos de España? La alusión a la opresión de los nativos indios, a la corrupción, la vaciedad, la sensualidad y ostentación de los dirigentes españoles, lleva sin duda un ligero acento político. En oposición con la anterior pieza del Teatro de Clara Gazul, y a pesar de la actitud completamente obsequiosa del Obispo de Lima para con la graciosa actriz, la iglesia se puso a buen recaudo. Desde este punto de vista, Merimée siguió también una tendencia moderna en el enjuiciamiento del régimen español en Sudamérica, que el "Ciudadano" Gregoire, en una Apología de Bartolomé de las Casas, leidá 22 de Floreal def Âno 8 en el Instituto Nacional, encontró muy bien caracterizinda: "En la enístoladedicatoria del prefacio de sus Incas, Marmontel atribuía al fanatismo la destrucción de los desgraciados indios. Desde hace medio siglo, cualquiera que supiese repetir con énfasis esas palabras, superstición, fanatismo, se creía un hombre de genio, y se consideraba un filósofo. Se comienta a advertir que es necesario algo más nara merecer este título. En 1777, en un onúscurlo intitulado: "Carta de un Lector del periódico francés v del Año literario". se le probó demostrativamente al señor Marmontel aue era falsa en sí su aserción, y contra. dictoria baio su pluma; que el orgullo, la ambición, el liber-

(13) Stendhal Racine y Shakesnenre, Paris (Calmann-I_evy), pár. 186.- Sohre el Virri:y Amat- es el histórico "Andrés de Ribera"- está muy dividido el juicio: Ricardo Palma (1. c. pág. 318) habla de su noca popularidad. L. Hernández Alfonso (VIrretnato del Perü, Madrid 1930, pág. $141 \mathrm{f}$ ), de su acción bienhechora: "Dejó buen recucrdo de su mando por sus aciertos y únicamente algunas debilidades de su vida privada (sostenla relaciones intimas con cierta muier, publicamente) perju. dican algo el buen nombre de este excelente gobernante". 
tinaje, la sed de oro, y no el celo religioso mal entendido, eran las vergonzosas pasiones que dominaban a los destructores del Nuevo Mundo". (14).

Algunos motivos de la Carroza puédense todavía considerar como descripciones auténticas de las condiciones peruanas en los últimos tiempos coloniales, que Merimée extrajo de otras partes del Diario de Hall o de las publicaciones de entonces de Sudamérica: la enajenación del culto religioso, que consigna el fondo de nuestra pieza, la significación del teatro, el lujo y fastuosidad de las carrozas de la aristocracia de la capital, nos son confirmados por las históricas representaciones de la cultura más reciente. (15). Pero Leguía nos advierte sobre esto: que el exotismo en Lima tiene sus límites: el Virrey Amat trató él mismo, por todos los medios, de imitar el modo de vida de Luis XV, de rodearse, a ejemplo francés, de una nobleza ostentosa, y construir en el extraño paisaje de las inmediaciones del Pacífico un segundo Versalles. (16) ¿Debía servir también esta analogía en sentido inverso, para el esclarecimiento de la Carroza? Esta imagen de las costumbres y el carácter peruanos es, quizá, coetánea del tiempo de la Restauración francesa, cuyos exponentes procuraban prolongar los rayos del sol del Antiguo Régimen en la Francia post-revolucionaria? Trahard se ha vuelto contra una tal interpre. tación actualista: Los liberales hubieran aplaudido, es cierto, calurosamente la pieza, los conservadores se hubieran escandalizado con su aparición y, más tarde, con su representación, pero este concento tendencioso no corresponde por ventura a la intención del poeta: "Merimée no pone en ello tanta malicia: es el público que la pone por él... ¿No es su burla más literaria que política?... No es una obra de polémica...."

(14) Ejemplar 01, 525 de la Biblioteca. Nacional de París, pág 25 (El juicio sobre la dorninación colonial española será suavizada en posteriores explicaciones por un juicio semejante sobre la colonización francesa $c$ inglesa). - Sobre la prehistoria de esta parte del exotismo en la literatura francesa, compárese G. Chinard: EI Exo: tismo americano en la literatura francesa en ei slglo XVI (París, 1911), y aci mismo: La America $y$ el sueño exótico en la literatura francesa en el stgio XVII y XVIII. (Paris 1913), especialmente pág. 373-389, 400-406,423 y otras; aqui scgún mi criterin no menciona las conocidas Cartns de una Peruana de Madame de Graffleny (ademós menciona las conocidas Caraffieny sobre las "Cartas de una Peruana", de Turgot); G. Atkinson, Las Relaciones de viajes del siglo XVII y ja evolución de las idens, París s.a., por ej. pág. 5 f. 10, 17, 20. 76. 100, 15\%. Compa. rese también M. Dodds, Las narraclones de viajes como fuentes del "Espiritu de las Leyes" de Montesquleu, Paris. 1929, pág. 114. ff: A. Feugére. Ravnal, Diderot $y$ algunos historiadores de las dos Indlas (RHLF 20, 1913); F. Baldensperger, "Voltaire $y$ los asuntos sudamericanos" (Rev. Litt. comp. 11, 1931) pág. 76 t.) La observación de Trahard de que Merimée ha introducido a Sudamérica en la literatura francesa, sólo debe referirse al joven movimiento romántico. Compárese E., v. Jan. "Para la Historia del Exotismo en la literatura francesa" (Zfe U 32, 1933, prig. 9 ff.)

(15) J. G. Legura, "Lima en el siglo XVIII" Lima 1921, pág. 21 f, 28 y otras.

(16) 1. c., pág. 27,30 y otras. 
(La Juventud de P. Merimée II, página 108). Pero no llama Merimée a esto "literaturizar" sobre las masas, en un importante impulso justamente para revisar su obra?

Se estará de acuerdo con Trahard cuando continúa él la cita trunca, asegurando que la Carroza no es ninguna "obra profunda"; pero justamente por esto se resarciría quizás al lector, si acertara a reconocer en él un juego espiritualmente irónico y no un juego rebelde realizado sin audacia. Queremos en lo sucesivo significar en pocas palabras por qué sostenemos la propia opinión de Merimée, expresada veinte años más tarde con respecto a Madame Brohan, que la Carroza fue escrita en un tiempo, "en que había un poco de valor para burlarse de los virreyes y de los obispos".

Los gobiernos franceses de la Restauración, en lo referente al problema de la emancipación hispanoamericana, han impulsado por dos razones una política más o menos reaccionaria: porque las tepdencias revolucionarias, republicanas y libertarias que predominaban en los movimientos de independencia de Sudamérica, contradecían ya por dos razones generales los Principios de la Restauración y de la Santa Alianza, $y$ porque se esperaba poner antes en vigencia en aquellos territorios de ultramar, la influencia francesa junto con la inglesa y la norteamericana, que la reglamentación de las condiciones coloniales decretada después por España, en unión con la España dinásticamente emparentada. Voces escépticas sobre estas tendencias-se hicieron suficientemente públicas ciertamente en el periodismo (por ejemplo, en los numerosos escritos del Abate de Piadt, enl roferencia ra este tema), y en los Despachos secretos, pero la política y la prensa oficial permanecieron fieles en apariencia al mismo fin, hasta la revolución de julio: sólo en 1830 estampó David la imágen del Libertador Bolívar y Luis-Felipe reconoció poco a poco la independencia de las diversas repúblicas hispano-americanas, fundadas durante el tiempo de la Restauración. En el año $1828 / 29$, hubo sin duda por ello un tema polémico, cuando se extrajo de la historia hispano-americana justamente la materia, en la cual aparecía la vida de los círculos representativos en las colonias españolas, bajo una luz muy poco favorable.

Pero creo que todavía se puede ir más lejos. Nadie afirmará que la ironía del segundo pocta francés, al que Goethe en sus Conversaciones con Merimée nombra siempre con particular elogio, que la ironía de Beránger es: "más literaria que politica". Entre sus canciones hay una que muestra una sorpren- 
dente analogía de motivos con nuestra pieza, la que, por eso, trascribimos:

\section{LA AMANTE DEL REY}

La Hija

Pasa en regio coche, madre, tirado por seis caballos, ¡qué divina criatura!

Es nuestra reina, ¿no es cierto?

\section{La Madre}

"Deja a la reina, hija mía, que no ostentó con descaro. ¿Vaya al diablo esa beldad! que es la querida del/rey" -Para sí dijo la moza: ) Bis de un rey quiero ser querida.

\section{La Hija}

"Mira en su cabeza el brillo de oro, perlas y diamantes, etras ¿tendrá en días de fiesta, más espléndidos vestidos?"

\section{La Madre}

"Pese a encajes y penachos, conozco muy bien sus rasgos.

De esta casa, sin zapatos huyó, pues era vaquera".

-Para sí dijo la moza:

de un rey quiero ser querida.

)

\section{La Hija}

“¿Quién pasa? Orgullosa y linda, llevando al trote su coche la baña a la otra en el polvo, la engancha, risas suscita, y huye". 


\section{La Madre}

"Rival de pomposo nombre, la dama es capaz de todo, hasta encamarse con el rey y reemplazar a la favorita".

-Para sí dijo la moza: de un rey quiero ser querida.

\section{La Hija}

"Defiende el rey a la que ama.

Montado un apuesto mozo

la vigila, y siendo hermoso, aspira dulce mirada".

\section{La Madre}

"Hijo de cepa famosa, sabe gustar y obtendrá el cordón azul en breve o alto puesto militar".

- Para sí dijo la moza: de un rey quiero ser querida.

Bis

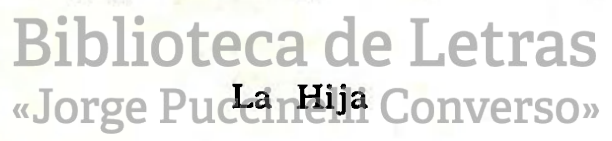

"Detiénese, y ella baja, se acerca un padre de aire noble.

$Y$ él besa con todo respeto

la mano que ella le tiende".

\section{La Madre}

"A esta oveja cuánto incienso hasta el obispo le ofrece; i él, que va a hablar del infierno al pecador que agoniza en un mísero pajar!". -Para si dijo la moza: de un rey quiero ser querida. 
"Y ahora ante ella desfila un matrimonio de aldeanos.

La novia es menos hermosa; empávase de ello el novio".

\section{La Madre}
"Nadas temas, que en su choza
la miseria cabal cuenta
el sudor que al pueblo cuesta
los vicios de esta mundana"
-Para sí dijo la moza:
de un rey quiero ser querida.

\section{) \\ ) $\mathrm{Bis}$}

Allí está con los regalos y el Estado de la ostentosa querida del amante; está el carruaje, el choque de ambas rivales; está finalmente el asaz amable Obispo contra la impertinente belleza. Cuál de los dos poetas es el que ha dado o el que ha recibido, eso dejémoslo estar allí, (17) que aquí nos interesa otra cosa: en Béranger, el amante es un rey, el escenario, un país de cualquier parte del mundo, de preferencia algún reino (quizá sea, pues, Francia), y sobre todo: cuando dos poetas, uno de los cuales, como Béranger, por ironía política, esbozan una imagen sermejante, no debe estar lejos el final, ya que la realidad misma les guió la pluma con todas las influencias literarias reciprocas posibles:

El que ha echado una mirada de contorno en la historia de la Restauración francesa, no irá mucho tiempo en busca de analogías con nuestra Carroza de la Comunión (18). Detrás del cuadro de Andrés de Ribera, parece hacerse presente ceremoniosamente, a pesar de todas las caricaturescas deformaciones, la imagen del declinante Luis XVIII: la edad, la gota v la real costumbre que sobrevivió al Antiguo Regimen de rodearse de favoritas y de favoritos - asi lo refieren las crónicas de la énoca y los modernos biógrafos-, le desnniaron al rev. en los últimos años de su vida, su natural volubilidad, convirtién-

(17) La poesía de Béranger apareció primeramente en las Ultimas Canclones. (1834. 51). Esto no quiere decir mucho. En el Prefaclo del tomo aparecido en 1833, el pocta mismo nos comunica que muchas poesias del tiempo de la Restauración sólo fueron publicadas ahora por él. "para completar estas especies de memorias cantadas que yo publico desde 1815".

(18) Sobre las muchas obras literarias, en las que juega un rol una carroza, y que por ello han podido influenciar a Meriméc, compárese la edición Trahard, pag. $4 \bar{y} \bar{y}$. 
dolo, políticamente, en una especie de muñecón de paja: "La edad y la enfermedad han contribuido, tanto como las sonrisas de madame de Cayla, a esta prematura abdicación" (19). Nos es comprobado también que no le va a la zaga a la liberalidad del rey para con su "favorita del último momento" (de la Gorce), o, como él mismo lo dijo, con el "consuelo de mis últimos años", la de nuestro virrey, frente a la Perricholi. $¿$ Deben frente a esto determinar con más exactitud los historiadores, que tienen tiempo para comparar en este punto menos fuentes unívocas, cómo le sienta al amor senil del rey la imagen de la Perricholi?. ¿Sólo ha fingido ella - como la Perricholi-, o ha rechazado muy sinceramente los importantísimos regalos del rey (François-Primo. Pág. 225-227), y solamente le ha atribuido a ella la maledicencia, una "rara habilidad para conseguir sus fines" y una "frivolidad picante"? (Id. pág. $180 \mathrm{ff}$.). No está uno muy equivocado al aceptar que, junto a Béranger ("Ven entre nosotros..." y otros) y Balzac (Coronel Chabert, Los Empleados), Meriméc se ha dado también el trabajo de poner a salvo en la literatura el rol de esta dama, que dio motivos en la sociedad francesa del tiempo de la Restauración para muchas cuchufletas y mezquinas rivalidades.(20).

¿Era ella capaz, como muchas damas llenas de quimeras por el "Genio del Cristianismo", de humildad y renuncia de las vanidades en el servicio de una fe, o sólo fungía, graciosa y galante, de mediadora entre "Trono y Altar", las dos autoridades y poderes dominantes de la 'época? (21). Pero Merimée ha dejado juguetonamente en suspenso esta cucstión en la descripción del Garrebatonde piedadeaela Perricholi.

Cerramos con llave nuestras comparaciones con dos paralelos de carácter más problemático. La "Amante del Rey" de Béranger, era, en Merimée, una "Amante del Virrey". La munarquía de la Restauración en Francia, no fue tampoco una soberanía con fuerza propia, sino una de segunda mano, por İa gracia de los estados vencedores y del dominio emanado de la Santa Alianza. Nadie lo sabía mejor que el propio Rey Luis, simpático en su misma ironía. François-Primo refiere una de

(19) J. Francois-Primo, Ia vlda nrlenda de Iuls XVIII. Paris. 1938, pác. 257; compsrese P. de la Gorce, Luls XVIII (La Restauraclón), París 1926, pág. 298, 306.

(20) Sobre los primeros amores del Rey, la orgullosa Madame de Balbi, tan persis. tonte en sus peticiones y la actriz Mile. Bourgoin, compárese Francois-Primo,pág.

(21) Luis XVIII se negó de primera intención a recibir la Extremaunción. "Como las ruerzas aei cntermo venlan de agolarse, agitó a la corte un gran temor, el de los deberes religiosos.... Se recurró, no sin cierta humillación, a la favorita, maaanie de Cayla. Esta logró lo que no pudieron las otras. Fue llamado un cura...." (de la Gorce, 1. c. Pág. 321). 
las más finas anécdotas que sobre él circulan: "Se sabe también que, al recibir para una comida a los soberanos extran. jeros, él fue el primero en sentarse a la mesa. Hay prisa para interpretar este gesto como una demasía de orgullo. Es un error: había querido simplemente mostrar que él no estaba en su casa. Eso era a la vez una gentileza y una lección..." (I, c. Pág. 258).

Con muchos otros usos del tiempo pre-revolucionario, fue revivida también desde la Restauración la ostentación de la carroza, con la que su Majestad pretendía representar dig. namente su poder. El único monumento del festival de la Coronación del Rey Carlos X en Reims (1825), es hasta ahora el precioso carruaje de la "Consagración de Reims", cuyas pomposas talladuras y brillantes oros no deja de admirar ningún francés que visita en nuestros días los históricos sitios de Versalles. En esta pieza capital del inventario, que de ninguna manera aparece en la escena, se simboliza, pues, para los lectores y espectadores de la "Carroza del Santo Sacramento" el Antiguo Régimen y la reacción en los tiempos de Merimée.

La historia peruana de la Perricholi, tal es nuestro final, que Merimée encontró probablemente en el Diario de Viaje de Hall, le ofreció a éste no solamente un modelo para un cuadro espiritual, psieológico y romántico, sino también la oportunidad para un retrato político, literariamente encubierto. Hay todavía una cuestión cronológica: cuando apareció la pieza por primera vez en la Revue de París, hacía ya varios años que Luis XVIII habia muerto, y es imaginable, aunque no verosimil, que nuestro poetac hubieseGideado aún en su tiempo la encubierta caricatura. Deberíamos aceptar que la pieza ya había sido escrita antes - Luis XVIII murió en 1824, la traducción francesa del original, que pudo haber leído ya Merimée antes en el original en inglés, tiene fecha de 1825-y ( ¿por razones de la censura o de la piedad?) sólo fue entregada a la publicidad algunos años más tarde. Por mucho que lo miremos, no habla en contra de una tal presunción.

(Traducción directa del alemán por Ernesto More) 